\title{
Desarrollo de competencias en el proceso de instrucción
}

\author{
Clara Jeannet Flores Delgado*
}

clara_jeannet@hotmail.com

Arriola Miranda, María Angelina, et al.

Trillas, 2007

Es tema de actualidad el desarrollo de competencias no sólo en el ámbito escolar, sino en el laboral, en este último, se ha creado el Sistema Normalizado y de Certificación de Competencia laboral. El libro objeto de análisis, nos presenta la teoría, acompañada de ejercicios prácticos para el diseño e impartición de cursos de capacitación que cumplan con dicha norma.

Comienza con un esbozo de lo que es la andragogía, es decir, aprendizaje adulto, haciendo hincapié en las reflexiones que al respecto hay que promover: de contenidos, de procesos y de premisas. Asimismo, podemos encontrar conceptos básicos sobre las teorías del aprendizaje, teorías de la motivación para la capacitación, algunos tipos de contingencias en el desarrollo del curso y por último una amplia gama de técnicas instruccionales, con una breve descripción de su propósito, ventajas y desventajas.

En el capítulo 2 se desarrolla la planeación instruccional, que consiste en decidir, qué objetivos se desean alcanzar (para plantear tales objetivos se presentan algunas sugerencias sobre las taxonomías más usadas), qué contenidos se van a impartir, cómo se organizarán y qué estrategias o técnicas se emplearán. Una vez decidido lo anterior, los materiales de enseñanza deberán secuenciarse y organizarse para su presentación y proceder a elegir los medios para el proceso de capacitación, sin perder de vista el impacto que el plan tendrá en las competencias cognitivas, afectivas y sociales del capacitando.

En el desarrollo de competencias son de suma importancia los resultados esperados en términos de conocimientos, habilidades y actitudes, por ello, es necesario contar con evidencias de aprendizaje que lo demuestren. Estas evidencias, según la norma nacional del instructor son: producto (exámenes, informes, reporte de contingencias y lista de verificación); conocimiento (manejo teórico de un proceso o teoría, se obtiene a través de entrevistas, discusión de casos o situaciones problema); desempeño (comportamientos del capacitando que denotan su aprendizaje) y por último, actitudes (se evalúan a partir de la participación e iniciativa y se encuentran integradas en las evidencias anteriores). 
El capítulo 3 nos ofrece los conceptos generales de evaluación y lo que debe considerarse en la evaluación de la capacitación que Kirkpatrick clasifica en los niveles de reacción, aprendizaje, comportamiento y resultados; mismos que indican los grados de profundidad en el proceso de aprendizaje. En la evaluación de reacción la conducta observable es lo más importante; en

la evaluación del aprendizaje se considera el conocimiento adquirido; la evaluación del com-portamiento considera la amplitud con que los participantes cambian su comportamiento en su puesto de trabajo como resultado de la capacitación. En este sentido, no basta con "saber", es necesario "saber hacer". Por último, la evaluación de resultados tiene que ver con aspectos tangibles, producto de la capacitación como: aumento de las ventas, mayor productividad, ganancias mayores, menor rotación de personal, etc.

Se presentan algunas técnicas de evaluación como la documental, de campo o discursiva. De igual manera, se muestran algunos instrumentos de evaluación como listas de cotejo, guías de observación, ejercicios prácticos, cuestionarios, entre otros. Se dan las cuatro etapas para la construcción de instrumentos de evaluación como son: la secuencia instruccional, elaboración de reactivos, ensamble de instrumentos y validez y confiabilidad de los mismos.

El capítulo 4 comienza por definir lo que son los materiales didácticos y la manera de generarlos sin soslayar que se trata de capacitación para adultos, por lo que deben considerarse los factores físicos que intervienen como la visión, la capacidad auditiva, el tiempo transcurrido en la generación de respuestas, etc., así como los factores intelectuales. La motivación es otro aspecto fundamental en la creación de los materiales pues es indiscutible que lo que "mueve" a un adulto a aprender es distinto a lo que hace un joven.

De la mano del anterior, el capítulo 5 hace referencia a la "tecnoenseñanza", mejor conocida como "microenseñanza" que nos marca aspectos fundamentales en la planeación de un curso y particularmente de cada sesión.

Entre las habilidades a desarrollar está la de empezar siempre con una inducción cuya función es la de captar la atención y el interés de los capacitandos, previo a la exposición de un tema o contenido.

La segunda habilidad se refiere a la comunicación que implica transmisión y recepción, por lo que el lenguaje debe ser preciso, sencillo, reiterante y coherente. Otro aspecto es la variación del estímulo que ayudará al capacitador a retener o captar la atención, pues estudios diversos coinciden en que las personas retienen la información de diversas formas: leyendo, escuchando, viendo y todas las combinaciones resultantes. 
Organizar de manera lógica una sesión permite comunicar las ideas y propicia la participación, siempre y cuando se tenga un manejo y control adecuado del grupo.

El libro está diseñado como un curso-taller, por lo que dar una reseña de él sin obviar aspectos importantes en su contenido es una tarea prácticamente imposible. Es un libro obligado para todos aquellos que estén interesados en los procesos de capacitación para adultos pero también puede servir de guía en el diseño de cualquier curso formal.

Los contendidos se plantean de manera dinámica y se complementan con ejercicios de práctica, ejercicios de reflexión, mapas conceptuales y evaluaciones que a la vez que ayudan en el propio aprendizaje nos muestran la pauta a seguir en el diseño instruccional. 